\title{
CIDADES EDUCADORAS EM PORTUGAL
}

\section{EDUCATING CITIES IN PORTUGAL}

\author{
EDUCAR CIUDADES EN PORTUGAL
}

Paulo Alexandre Miranda Louro1

\section{RESUMO}

0 conceito de cidade educadora norteia a ação política de cerca de 500 governos locais por todo 0 mundo. O papel dos governos locais é hoje fundamental na definição das políticas públicas, pelo que a análise do que tem sido a intervenção no quadro das cidades educadoras, no caso português, dá conta daquilo que são as tendências na assunção da transversalidade da educação enquanto elemento fundamental na definição das políticas territoriais. É com a mirada das cidades educadoras que olhamos para a forma como os governos locais portugueses têm procurado desenvolver uma ação local que responda aos atuais problemas globais.

PALAVRAS-CHAVE: Cidades educadoras, Governos locais, Rede portuguesa.

\section{ABSTRACT}

The concept of an educating city guides the political action of around 500 local governments around the world. The role of local governments is now fundamental in the definition of public policies, so the analysis of what has been intervention in the context of educating cities, in the Portuguese case, gives an account of what are the trends in assuming the transversality of education as a fundamental element in the definition of territorial policies. It is with a view to educating cities that we look at how Portuguese local governments have sought to develop local action that responds to current global problems.

KEYWORDS: Educating cities, Local governments, Portuguese network.

\section{RESUMEN}

El concepto de ciudad educadora guía la acción política de unos 500 gobiernos locales en todo el mundo. El papel de los gobiernos locales es fundamental hoy en la definición de políticas públicas, por lo que el análisis de lo que ha sido la intervención, en el contexto de las ciudades educadoras, en el caso portugués, muestra cuáles son las tendencias en la suposición de la transversalidad de la educación como elemento fundamental. en la definición de políticas territoriales. Es con la mirada de las ciudades educadoras que vemos cómo los gobiernos locales portugueses han tratado de desarrollar una acción local que responda a los problemas globales actuales.

PALABRAS CLAVE: Ciudades educadoras, Gobiernos locales, Red portuguesa.

\section{CONSIDERAÇÕES INICIAIS}

O papel dos governos locais tem sido referenciado, nos últimos anos, (OECD, 2018) como um dos antídotos mais importantes no combate aos efeitos desagregadores da globalização.

1 Doutorando da Universidade Jaume I em Castellón, Espanha. Docente no Instituto Superior de Educação e Cièncias (Lisboa). Coordenador do Mestrado em Gestão Autárquica. 
Com o progressivo enfraquecimento dos Estados Nação os governos locais têm surgido como elementos estruturantes e fundamentais na definição das políticas públicas.

É neste enquadramento que procuraremos dar conta do papel dos governos locais portugueses no âmbito do conceito de cidade educadora, uma vez que se trata de um paradigma de governação local que tem obtido um bom acolhimento junto dos municípios portugueses, como o demonstra o fato de 76 deles, $25 \%$ do total dos municípios portugueses, pertencerem à Associação Internacional de Cidades Educadora (AICE).

\section{CONCEITO DE CIDADE EDUCADORA}

O reconhecimento da importância de uma população culta (Alfieri, 94, citado por Villar, 2001) e a abertura da comunidade à escola, disponibilizando os seus recursos constitui 0 primeiro momento da perspectiva de que a cidade educa.

A ideia de que a educação deveria atingir todos os públicos, e não apenas as crianças e jovens, faz com que se olhe para a diversidade de elementos educadores da cidade e se perspetivem, também, os equipamentos e instituições da cidade como recursos, mesmo para os destinatários da educação formal.

Quando em 1990 o município de Barcelona declara (Ayuntamiento de Barcelona, 1990) que "... a educação dos meninos, jovens e cidadãos em geral não é só responsabilidade dos estratos tradicionais (Estado, família e escola) mas também dos municípios, das associações, das indústrias culturais, das empresas com vontade educadora...", defendendo também a importância do fortalecimento do tecido educativo e da formação proporcionada pelos agentes educativos não escolares, tínhamos atingido um terceiro momento de que o movimento das cidades educadoras e o conceito de cidade educadora parecem ser legítimos representantes.

Também Paulo Freire na sua obra "Educação na cidade" defende a ideia de mudar a cara da escola (p.24), o que obrigaria, necessariamente, a uma outra relação com a cidade.

A AICE rege-se por uma carta de 20 princípios que poderíamos sintetizar da seguinte forma:

QUADRO 1: Síntese dos princípios da Carta das cidades educadoras

\begin{tabular}{|l|l|l|}
\hline & & TOPICO \\
\hline 1 & Igualdade & Construir uma cidade que cumpre o direito à igualdade \\
\hline 2 & Diversidade & $\begin{array}{l}\text { Construir uma cidade que promove a educação na/para } \\
\text { a diversidade }\end{array}$ \\
\hline 3 & Diálogo & Construir uma cidade que encoraja o diálogo e a ação \\
\hline
\end{tabular}




\begin{tabular}{|c|c|c|}
\hline & Intergeracional & entre gerações \\
\hline 4 & Qualidade de vida & $\begin{array}{l}\text { Construir uma cidade com políticas locais de promoção } \\
\text { da qualidade de vida }\end{array}$ \\
\hline 5 & Política Educativa & $\begin{array}{l}\text { Construir uma cidade onde a política educativa é } \\
\text { assumida (reivindicada) de forma ampla }\end{array}$ \\
\hline 6 & $\begin{array}{l}\text { Responsabilidade } \\
\text { Partilhada }\end{array}$ & $\begin{array}{l}\text { Construir uma cidade que decide porque conhece os } \\
\text { problemas e as necessidades, porque ouve as pessoas } \\
\text { e que tem em conta, nos processos de decisão, o seu } \\
\text { impacto formador/educador }\end{array}$ \\
\hline 7 & Identidade & $\begin{array}{l}\text { Construir uma cidade que tem identidade e que a } \\
\text { promove e a reconstrói com todos, todos os dias }\end{array}$ \\
\hline 8 & $\begin{array}{l}\text { Planeamento } \\
\text { urbano }\end{array}$ & $\begin{array}{l}\text { Construir uma cidade onde o planeamento urbano é um } \\
\text { fator pleno e rico de integração }\end{array}$ \\
\hline 9 & Participação & $\begin{array}{l}\text { Construir uma cidade participativa com base na } \\
\text { informação e na ética }\end{array}$ \\
\hline 10 & Acessibilidade & $\begin{array}{l}\text { Construir uma cidade com espaços físicos adequados } \\
\text { para todos e para todas }\end{array}$ \\
\hline 11 & Sustentabilidade & $\begin{array}{l}\text { Construir uma cidade que promove a sustentabilidade e } \\
\text { a saúde }\end{array}$ \\
\hline 12 & Governança & $\begin{array}{l}\text { Construir uma cidade onde os processos de governação } \\
\text { apontam uma perspectiva educadora }\end{array}$ \\
\hline 13 & Cultura & $\begin{array}{l}\text { Construir uma cidade que se relacione com o mundo e } \\
\text { que garanta liberdade de fruir a informação e a cultura }\end{array}$ \\
\hline 14 & Formação & $\begin{array}{l}\text { Construir uma cidade que transmita de forma informal e } \\
\text { que esse seja um processo de formar cidadãos } \\
\text { formadores de convivência }\end{array}$ \\
\hline 15 & Inclusão & $\begin{array}{l}\text { Construir uma cidade onde todos e todas se sintam } \\
\text { significativos (na sociedade e no local de trabalho) e } \\
\text { que o sejam ao longo da vida }\end{array}$ \\
\hline 16 & Coesão & $\begin{array}{l}\text { Construir uma cidade da coesão seja com os seus seja } \\
\text { com aqueles que a querem integrar (imigrantes, } \\
\text { refugiados, etc.) }\end{array}$ \\
\hline 17 & Colaboração & $\begin{array}{l}\text { Construir uma cidade que, na parceria entre } \\
\text { administração e sociedade civil, seja capaz de } \\
\text { desenvolver atividades significativas }\end{array}$ \\
\hline 18 & Associativismo & $\begin{array}{l}\text { Construir uma cidade promotora do associativismo com } \\
\text { sentido de co-responsabilidade }\end{array}$ \\
\hline 19 & $\begin{array}{l}\text { Acesso à } \\
\text { informação }\end{array}$ & $\begin{array}{l}\text { Construir uma cidade que garanta a informação com } \\
\text { critério e legibilidade garantindo assim a permanente } \\
\text { busca pela integração de todos e todas }\end{array}$ \\
\hline 20 & Cidadania & $\begin{array}{l}\text { Construir uma cidade que promova e cumpra, com } \\
\text { todos e todas, o bem comum e uma cidadania } \\
\text { democrática. }\end{array}$ \\
\hline
\end{tabular}

Fonte: Louro (2017)

Atualmente com quase 500 membros oriundos de 37 países, a AICE, constitui um significativo movimento que procura consubstanciar os 20 princípios acima enunciados. 


\section{A REDE PORTUGUESA (RTPCE)}

Entre 1990 e 2003 a participação portuguesa neste movimento foi confinada às cidades de Porto e Lisboa.

É em 2004 e a pretexto da discussão da revisão da Carta das Cidades Educadoras que se inicia a organização de uma rede portuguesa que se tem vindo a materializar em atividades como: encontros nacionais, boletim de boas práticas, congressos nacionais, formação de agentes educadores e grupos de trabalho temáticos.

A rede portuguesa procura criar espaços de encontro entre os 76 municípios que dela fazem parte, também através de uma página de facebook, onde se divulgam algumas das iniciativas que os vários municípios desenvolvem e que se enquadram no conceito de cidade educadora.

\section{Congressos Nacionais}

Espaços de encontro por excelência são os congressos nacionais que vão já na sua VIII edição e que têm sempre uma temática chave que serve de enquadramento para a apresentação de boas práticas. Para que se possa ter a perspectiva das temáticas dos congressos:

QUADRO 2: Temáticas dos congressos nacionais da RTPCE

\begin{tabular}{|l|l|}
\hline ANO & TEMÁTICA \\
\hline 2006 & A cidade é educadora \\
\hline 2007 & Municípios educadores vs territórios multiculturais \\
\hline 2009 & $\begin{array}{l}\text { A Educação como património e o património como agente } \\
\text { educador }\end{array}$ \\
\hline 2011 & $\begin{array}{l}\text { A cidade educadora e o ambiente: problemática global- respostas } \\
\text { locais }\end{array}$ \\
\hline 2013 & A cidade educadora é a cidade que inclui \\
\hline 2015 & Cidades participadas/ Cidades adaptadas (veis) \\
\hline 2019 & Criar (na) cidade \\
\hline
\end{tabular}

Fonte: elaboração própria

A análise das temáticas base de cada congresso dá conta da diversidade de práticas enquadráveis em políticas que tenham por base o conceito de cidade educadora. 
Depois de um tema geral no I congresso, as bases de apresentação de boas práticas passaram, no II Congresso, pelo reconhecimento da multiculturalidade dos territórios, permitindo a discussão em torno da riqueza dessa multiculturalidade, das oportunidades de encontro e convivência que a diversidade constitui, sendo que a complexidade actual dos territórios, 0 receio face ao que é diferente, são, nos tempos atuais, dos maiores desafios que se colocam aos governos locais e aos agentes educadores do território.

Em 2009 decorreu em Évora o congresso nacional, cidade património da humanidade, pelo que a temática do património e do seu papel educador foram a base da apresentação de boas práticas, nomeadamente o papel da memória e a forma como a intervenção dos governos locais pode "combater" o presentismo das sociedades atuais e a identificação das raízes culturais como elemento agregador das comunidades.

No congresso seguinte as temáticas ambientais e as questões da sustentabilidade foram o mote da partilha entre os participantes. O repto "Pensar global, agir local" esteve presente nas apresentações em que as cidades em transição como resposta aos desafios das alterações climáticas e a Educação para a Sustentabilidade foram temáticas bem presentes. Interessante foi a discussão do conceito de Paisagem Educadora, salientando a importância de um ambiente de qualidade para a promoção da qualidade de vida de tod@s.

A inclusão foi tema do congresso seguinte permitindo um olhar de vários pontos de vista, nomeadamente a inclusão social, uma vez que uma cidade inclusiva se preocupa em fornecer a todos os seus habitantes serviços básicos de qualidade independentemente da etnia, status, sexo ou nível socioeconómico; da inclusão económica, que permita igualdade no acesso ao emprego, ás políticas económicas e na promoção do empreendedorismo; na inclusão política, que garante os direitos e liberdades dos seus cidadãos e promove a participação social e política para que os líderes da cidade possam tomar melhores decisões com conhecimento de causa e democraticamente; a inclusão cultural, em que a diversidade cultural está consagrada como elemento fundamental; a inclusão digital que democratiza 0 acesso às tecnologias e inclui as pessoas digitalmente; a inclusão de identidade e género que promove a igualdade e a não discriminação de acordo com a legislação e com o respeito pelos direitos humanos; a inclusão de desenvolvimento que promove o desenvolvimento local nos seus diversos domínios.

A participação, a necessidade de adaptação dos territórios e a necessidade de envolvimento e a participação de todos na construção do futuro foram reflexões fundamentais no congresso subordinado ao tema Cidades participadas/ Cidades adaptadas(veis). Aí se falou sobre a necessidade de equilíbrio entre as dimensões económica, ambiental e social e da 
importância de os territórios terem uma visão prospectiva que lhes permita antecipar tendências e evoluções, no sentido de que possam adaptar-se a um mundo em constante transformação. A construção participada e colectiva facilita também a adaptação a novos usos dos espaços públicos, sempre no sentido de estimular a diversidade, a convivência e a partilha.

A Identidade nas cidades foi o tema do congresso de 2017, tendo sido identificada como um fator crucial na implementação de políticas públicas mais inclusivas e sustentáveis, uma vez que o sentimento de pertença e da relação entre o(s) cidadão(s) e o seu território resultam num compromisso entre tod@s e entre as pessoas e o território. As experiências apresentadas procuraram indicar os caminhos em que, face à globalização, importante seria trabalhar em compromissos de coesão cultural onde a confiança, a cooperação, a participação, a tolerância e a diversidade estejam presentes.

No recente congresso de Maio o tema foi Criar (na) cidade, tendo sido apresentadas experiências que equacionavam a forma como os espaços e ambientes públicos, que permitem a fruição da arte, do convívio social, da troca de saberes e experiências intergeracionais, enquanto momentos de construção e partilha de saberes, são determinantes na construção de territórios mais equitativos e de acordo com os princípios da carta das cidades educadoras.

Os congressos nacionais têm, em média, a apresentação de 60 boas práticas de municípios e de várias conferências plenárias com convidados nacionais e internacionais, experts no tema em debate.

\section{a. Encontros Nacionais}

Os Encontros Nacionais realizam-se em diversos locais do país (procurando descentralizar os mesmos), sendo normalmente realizados 3 por ano. São momentos de encontro e partilha de experiências (muitas vezes em contexto informal) e de organização da própria rede face à sua actividade regular, aos desafios que os municípios vão enfrentando e às demandas efectuadas pela própria AICE.

\section{b. Grupos Temáticos}

A RTPCE promove grupos temáticos decorrentes dos interesses e motivações dos vários municípios membro. O repto é lançado por um dos municípios e têm vindo a ser organizados grupos temáticos nas seguintes áreas: Educação para o Consumo, Segurança na Cidade, Voluntariado, Projeto Educativo Local, Participação e Democracia, Inclusão, Experimentar para Aprender (dedicado ao ensino das ciências) e Educação ao longo da vida. 
Nestes grupos partilham-se experiências, clarificam-se conceitos, discutem-se estratégias, contornam-se dificuldades e organizam-se actividades, nomeadamente seminários com a participação de experts, e produzem-se documentos (nomeadamente o documento base para a construção do projecto educativo local).

\section{c. Boletim de boas práticas}

O Boletim é, no entanto, um elemento estruturante da partilha de experiências que é um dos objetivos essenciais desta rede. Por essa razão uma análise das boas práticas apresentadas no Boletim será sempre um bom indicador daquilo que é valorizado pelos municípios portugueses no quadro das cidades educadoras.

Os boletins estão disponíveis em http://www.edcities.org/rede-portuguesa/

A análise refere-se aos boletins publicados entre 2006 e o inicio de 2018, num total de 33 números.

Para a análise das boas práticas apresentadas pelos municípios utilizaram-se os descritores da AICE, sendo os seguintes os resultados:

Quadro 3: Análise de boas práticas apresentadas no boletim da RTPCE

\begin{tabular}{|l|l|}
\hline DESCRITOR & $\begin{array}{l}\mathrm{N}^{0} \\
\text { PROJETOS }\end{array}$ \\
\hline Sistema Educativo & 225 \\
\hline Cultura e Ócio & 139 \\
\hline Saúde e Desporto & 76 \\
\hline Ambiente & 75 \\
\hline Artes e Humanidades & 65 \\
\hline Politica e Administração & 45 \\
\hline Associativismo e participação & 40 \\
\hline Formação Permanente & 33 \\
\hline Desenvolvimento Urbano & 32 \\
\hline Informação e Documentação & 31 \\
\hline Civismo e convivência & 31 \\
\hline
\end{tabular}




\begin{tabular}{|l|l|}
\hline Desenvolvimento Socio-Económico & 28 \\
\hline Desenvolvimento Pessoal & 25 \\
\hline Diversos & 21 \\
\hline Ciência e Tecnologia & 13 \\
\hline
\end{tabular}

Fonte: elaboração própria

Algumas conclusões decorrentes da análise das boas práticas apresentadas:

- Grande parte dos mesmos decorrem em escolas ainda que o público-alvo não seja exclusivamente escolar. A alocação do projecto cidade educadora aos sectores/ divisões de educação dos municípios favorece uma maior divulgação de acções ocorridas neste âmbito.

- Os alunos são o principal público-alvo das ações e projetos embora se verifique uma cada vez maior tendência para que seja a comunidade o destinatário, o que significa uma maior preocupação com todos os elementos da cidade. A apropriação do conceito de educação ao longo da vida está fazendo, progressivamente, seu caminho entre técnicos e autarcas.

- A partir de 2009 e com maior ênfase nos últimos anos encontramos boas práticas relacionadas com a sustentabilidade, o que não deixa de ser um sinal positivo, até decorrente dos objectivos de desenvolvimento definidos pelas Nações Unidas.

- Desde 2013 começamos a verificar uma evolução com projetos participativos da comunidade. Para tal muito tem contribuído a implementação dos Orçamentos Participativos em diversos municípios, tendo sido Portugal o $1^{\circ}$ país a ter um orçamento participativo nacional.

- Nos últimos três anos encontramos boas práticas relacionadas com o empreendedorismo. Os governos locais têm-se apropriado do seu papel fundamental enquanto elementos favorecedores do desenvolvimento local e este é um dos reflexos desse papel.

- Questões relacionadas com a mobilidade e o espaço público são também cada vez mais frequentes, assim como as questões dos direitos humanos, multiculturalidade, imigração e refugiados, traduzindo ao nível local a perspectiva de implementar políticas que dêem resposta aos grandes desafios globais.

- De salientar, sempre, o papel importante atribuído aos equipamentos culturais da cidade como museus, bibliotecas, espaços de sensibilização ambiental, etc., o que reflecte o papel atribuído aos equipamentos de educação não formal. 
Percebemos, pelo quadro apresentado, da heterogeneidade de iniciativas desenvolvidas no quadro das cidades educadoras e da diversidade de áreas abrangidas pela intervenção dos municípios portugueses para além das questões relacionadas com a educação formal.

Perguntámos também a políticos e técnicos dos municípios membro quais as potencialidades e aspetos positivos do Boletim, tendo obtido, genericamente, respostas como:

- Recolha de boas práticas de outros municípios;

- Partilha de experiências;

- Inspiração para ações que melhoram a qualidade de vida dos nossos munícipes;

- Conhecer as preocupações que outros municípios vão sentindo;

- Apresentarmos projetos dos quais nos orgulhamos.

\section{CONCLUSÃO}

A vitalidade, indicada pela participação nas edições do Boletim, é reforçada com as restantes acções desenvolvidas pela RTPCE e que acima referimos.

Estas são formas de a cidade mostrar o que é, o que gosta de ser, projetando para todos e todas os seus valores e compromissos, é uma forma de a cidade dizer como é e não apenas, como tantas vezes ocorre em situações educativas, de dizer o que quer que os outros sejam.

Uma cidade educadora quer-se ativa, inovadora, estabelecendo redes, sustentável e com identidade, respeitando a diversidade e fazendo dela a sua força, potenciando a partilha e os vínculos que permitiram superar os desafios impostos pelas tendências globalizantes.

Esta tem sido uma das preocupações da rede portuguesa de cidades educadoras que esperamos, por sua vez, possa ser inspiradora da rede brasileira de cidades educadoras.

\section{REFERÊNCIAS}

AYUNTAMIENTO DE BARCELONA. La ciudad educadora. Ayuntamiento de Barcelona: Barcelona, 1990.

FREIRE, Paulo. A educação na cidade. São Paulo: Cortez Editora, 1995.

LOURO, Paulo. Angola, a descentralização e a participação: pistas para um caminho desafiante. Alameda, nº4. Lisboa: ISEC, 2017.

OECD (2018) Regions and Cities at a Glance. OECD: Paris VILLAR, M. A cidade educadora: instituto Piaget: Lisboa, 2001. 